\title{
Development of Microcontroller Based Two Stage Student Attendance Management System
}

\author{
${ }^{* 1}$ Hakan Üçgün, ${ }^{1}$ Enes İleri, ${ }^{1}$ Uğur Yüzgeç and ${ }^{1}$ Rıdvan Yayla \\ ${ }^{1}$ Faculty of Engineering, Department of Computer Engineering Bilecik Seyh Edebali University, Turkey
}

\begin{abstract}
The progress on today's technologies has brought many advantages. Wearable technologies, telecommunication, robotic systems, $3 \mathrm{~d}$ printers and many other applications provide great convenience for human life. Sensor technologies are also among these applications. Performing a process by controlling or co-operating the sensors also provides a significant benefit in eliminating difficulties for humans. One of the places where sensors are used is recognition systems. In the recognition process, the user materials are used such as the card, fingerprint, iris, face etc. Digital identification systems are recognition systems that can be done with various sensors and provide various benefits for the users. In the scope of this study, student attendance management system that comprises two stage control processes has been realized. At the first stage, the student ID card is read in the RFid card reader module and then the person information is checked from the database and go to the second stage. At the second stage, the fingerprint of the student is read by fingerprint sensor and the student is given the possibility to transition after the database control. Time and login information are recorded in the database when the student uses the system. Thanks to this system, it is aimed to get rid of some problems, such as sign someone else's, reading the student card someone else's, etc., in the student attendance management system.
\end{abstract}

Key words: Recognition Systems, Arduino, Student Attendance Management, RFid, Fingerprint

\section{Introduction}

Sensor-controlled systems are systems that make a decision based on a sensor measurement or value and change the system's operating structure according to the sensor results. Technological conditions cannot ignored in the progress of sensor technologies. Sensors shrinking in size with developing technology are classified according to usage purposes and places. Sensors are nowadays commonly used in many application areas such as IoT, intelligent homes, industrial automation, robotics control, etc. When looking the usage areas of the sensors, the applications used in various recognition systems are also seen. Various components such as RFid cards, fingerprint sensors, RGB leds and cameras are frequently used in recognition processes.

Recognition processes are based on the specific features like a human's face, fingerprint, palm, iris, or an object's, shape, size. Many data media and tools are preferred for recognition, such as smart cards, cameras, biometric sensors, OCR (optical character reader). In the performed applications, automatic recognition and reading of the identification marks play an importance role. Identification marks are recognized by the barcode, square code and RFid technology [1].

*Corresponding author: Hakan Üçgün, Address: Faculty of Engineering, Department of Computer Engineering Bilecik Seyh Edebali University, 11230, Bilecik TURKEY. E-mail: hakan.ucgun@bilecik.edu.tr, Phone: +90228141695 429 
RFid (Radio Frequency Identification) technology is the process of identifying living things or objects through radio waves. This technology allows identification of radio wave frequencies that are possessed by living things or objects. RFid hardware consists of an antenna and a microchip with RFid tag. RFid tags can store large amounts of data and write data quickly. RFid technology, which can be used in different environmental conditions, can communicate data for long distances thanks to its readers $[2,3]$.

Three different shapes in the fingerprint resemble arch, loop and whorl. These are considered unique for the fact that people's fingerprints are found in different shapes in each person. Recognition procedures are performed thanks to the comparison of the parameters of these forms in the fingerprints [4]. Fingerprint recognition systems offer many advantages to users in terms of reliability, system performance, ease of use and cost. It is one of the most frequently used methods among biometric recognition techniques [5].

In the scope of the study, the RFid card and the fingerprint sensors were used together to perform the student attendance tracking system. The system works in two stages. Firstly, the user card with RFid chip is read into the system and the student record is searched in the database. If there is no record of the student, new student registration is required. If registration is ok, fingerprint check state will start. The checking with fingerprint sensor is carried out at the second step; the user fingerprint is searched in the database including fingerprint records. If the relevant student is registered in the fingerprint database, entry to the checklist is made, otherwise fingerprint registration is required. In this study, the form screen with $\mathrm{C} \#$ language was designed and the database was designed for the registration process.

\section{Related Recognition System Studies}

Recognition systems are classified according to the characteristics of a living creature or object. Different hardware units such as plate, character, staff cards, magnetic cards, keys can be used in recognition process. Besides such hardware units, biometric data such as iris, fingerprint, palm, face, speech, DNA are used. In general, image-processing techniques are utilized in recognition systems. Each recognition process has advantages and disadvantages relative to each other. Recognition systems are generally preferred in application areas such as person tracing procedures, face detection, plate recognition, encrypted login process, etc.

Looking the similar studies, it is seen that there are many RFid based systems. In the study of Pala [6], RFid technology was proposed for e-attendance system application in a school. In the study, a system was developed that enables e-attendance using RFid readers and RFid tags. The system, which operates in certain classes of a school, is controlled through a central database and allows an economical, secure and rapid attendance.

Deniz et al. [7] realized an RFid lock system that allows the personnel working in educational institutions in order to easily enter the classrooms, rooms, laboratories and private areas where they want to enter. The system can record in real time and display the information of the last person entering the room. In this view, it can be seen from the outside that the personnel, who are in 
classrooms, rooms and laboratories. New personnel permit can be added or removed for each room upon request. The control board of the lock system is Arduino-based controller card.

Baykara et al. [8] developed a mobile software that allows use in the digital environment of signature system used in educational institutions. The developed software provides reporting with minimum error rate. By the intelligent attendance system developed using Near Field Communication (NFC) technology, when users interact with NFC tags, it is possible to track the attendance system according to their position and time.

\section{System Design and Used Components}

The work principle of the student attendance system is shown in Fig 1. The proposed system consists of Arduino Uno controller card, RFid and fingerprint sensors, Arduino and C\# programming language and MSSQL database. Taken data from RFid and fingerprint sensors are sent to the C\# user form in the PC via the Arduino card. In the processes performed on the form, the system is controlled by querying through the database. If the related student is registered in the database, it is recorded in the attendance list. Otherwise, it is asked to register the student by giving a warning window on the form screen.

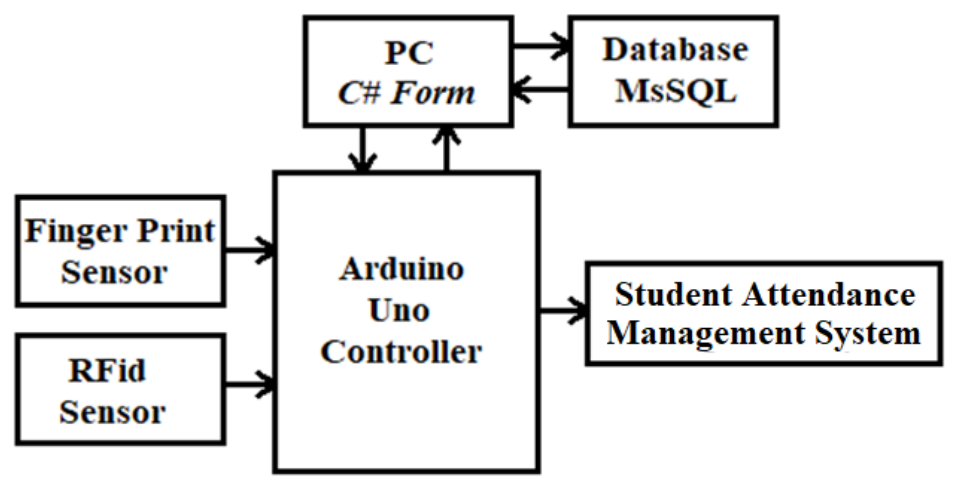

Figure 1. Student Attendance Management System Diagram

\subsection{Arduino Uno Controller}

Arduino cards are microcontroller cards with various peripheral units, which are developed as hardware and software open source, containing Atmel AVR based microcontrollers. It seems to have been used frequently in the field of embedded systems in recent years due to reasons such as open source, having a library for every sensor or integrated, cost less than other controllers cost. The programming language is the processing/wiring language.

The Arduino Uno R3 card is a controller card that uses an 8-bit Atmega328 microprocessor. There are 20 general purpose input / output pins on the card. There are 14 digital and 6 analog input/output of these pins. The card contains many peripheral units such as $16 \mathrm{MHz}$ crystal oscillator, $32 \mathrm{~KB}$ flash memory, 2 KB SRAM, 1 KB EEPROM. Figure 2 shows the Arduino Uno R3 card [9]. Arduino IDE environment is used for Arduino programming. The IDE environment can be used 
both as a compiler and as a code editor. The written code can be compiled and loaded into the Arduino card.

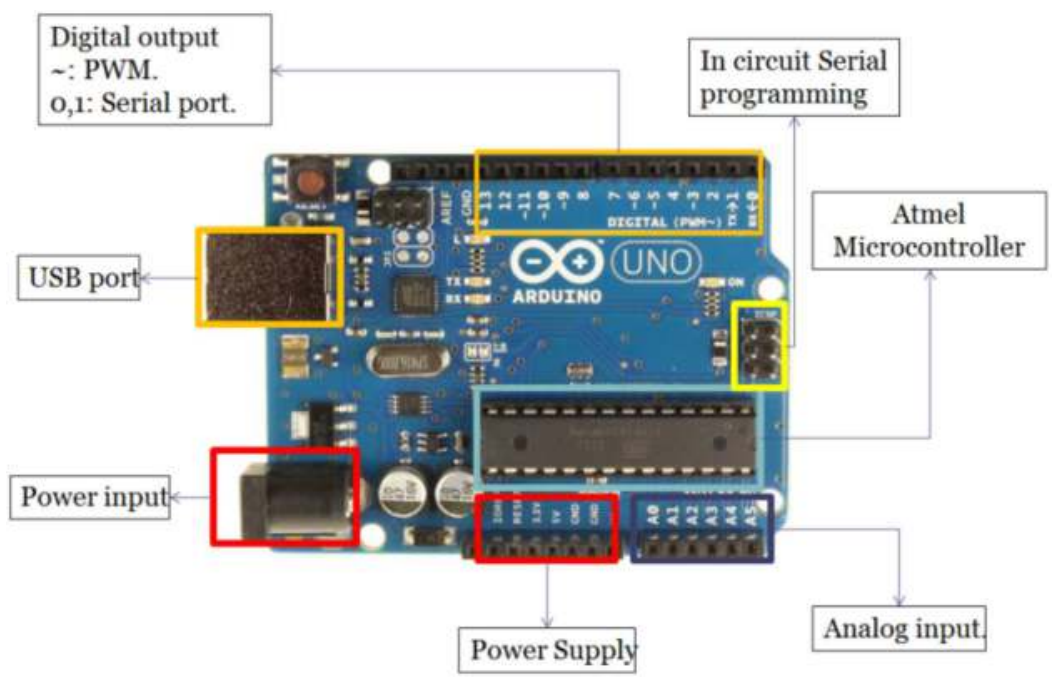

Figure 2. Arduino Uno R3 Board [9]

\subsection{RFid Card Reader Sensor}

In the RFid system, there are a tag and a reader built in from an antenna chip. Reader equipment is used to emit electromagnetic waves while tag equipment is used to receive electromagnetic waves sent. A passive RFid tag detects wave signals sent from the reader and uses these signals to operate the integrated circuit in the microchip. The microchip changes the digital information in waves and sends it back to the reader. This is the working principle of the RFid system [3].

RC522 RFid card reader sensor is used in the study. It is a small size sensor with low power consumption. It communicates at $424 \mathrm{Kbit} / \mathrm{s}$ communication rate. It can read and write on labels operating at frequency of $13.56 \mathrm{MHz}$. It can be used on many microcontroller cards, especially Arduino. The sensor, which supports different types of encryption on RFid, only supports cards operating at $13.56 \mathrm{MHz}$ frequency [10].

\subsection{Fingerprint Sensor}

The basic rationale for fingerprint encryption is based on the unique biometric finger structure of humans. The map-like structure at the tip of each human's fingers is different from each other. The fingerprint reading sensors identify the indentation in this area and store it in the memory. Then, when the same fingerprint is read, the structure at the fingertip is scanned and a map is extracted. Fingerprint control is performed by comparing the data in memory and the read data.

ZFM60 Fingerprint reader sensor module was selected in the study. This sensor, which makes fingerprint identification and authentication easily, is usually used on the cash register. It features 
a high-power DSP chip for image processing, feature detection and search operations on images. The flash memory can store 162 fingerprints [11].

Present simple formulae in the line of normal text where possible and use the solidus (/) instead of a horizontal line for small fractional terms, e.g., X/Y. In principle, variables are to be presented in italics. Powers of e are often more conveniently denoted by exp. Number consecutively any equations that have to be displayed separately from the text (if referred to explicitly in the text).

\subsection{C\# Form Design}

Form screens are designed by using C \# programming language in order to use the data obtained from computer environment. Forms are generally provided with the ability to add new records, check the attendance process, and to see what the users are which lesson about at what time. The student card and fingerprint datas obtained from sensors on Arduino are transferred to the computer environment with cable connection over port. In the future work, we consider using Bluetooth or Wi-Fi technology wirelessly for data transfer.

The data coming from Arduino is taken into the $\mathrm{C} \#$ form, and then the query is done through the database. For example; when a student named Ahmet reads his card, the information about the card is queried through the database and the card information is displayed on the form screen if the student info registered in the database.

In Figure 3, homepage and new registration forms for the RFid tag is shown. To explain what has been done in the homepage form, there are three buttons, registration, attendance, student info. When the buttons are pressed, the relevant forms are switched. In the registration form, the "RFid" section automatically receives the RFid card information sent via Arduino. In other sections on the form, registration information of the student is requested. After registration, student lists are displayed from the sub-section. The update, delete and display operations can be done via the buttons in the right panel.

\subsection{Database Design}

In the scope of the study, a database in MsSQL language was designed in order to keep the information of the students who are registered in the system or to be new registered and to use this information if necessary. Figure 4 shows the database table created for RFid operations. The student data such as RFid, first name, surname, department, etc., which is shown in the form screen shown in Figure 3, is recorded in the database.

There are four tables used in the database, named "DersBilgi", "YoklamaBilgi", "GirisCikisBilgi" and "OgrenciBilgi". In the database operations, the registration information of the student is taken first and the student is activated in the system. If the looking database process, when the student card is read, the ID information of the card is compared with the student information "OgrenciBilgi.OgrenciRFid", and if the match is made, the student's entry information is added to the database. The same processes apply in fingerprinting too. 


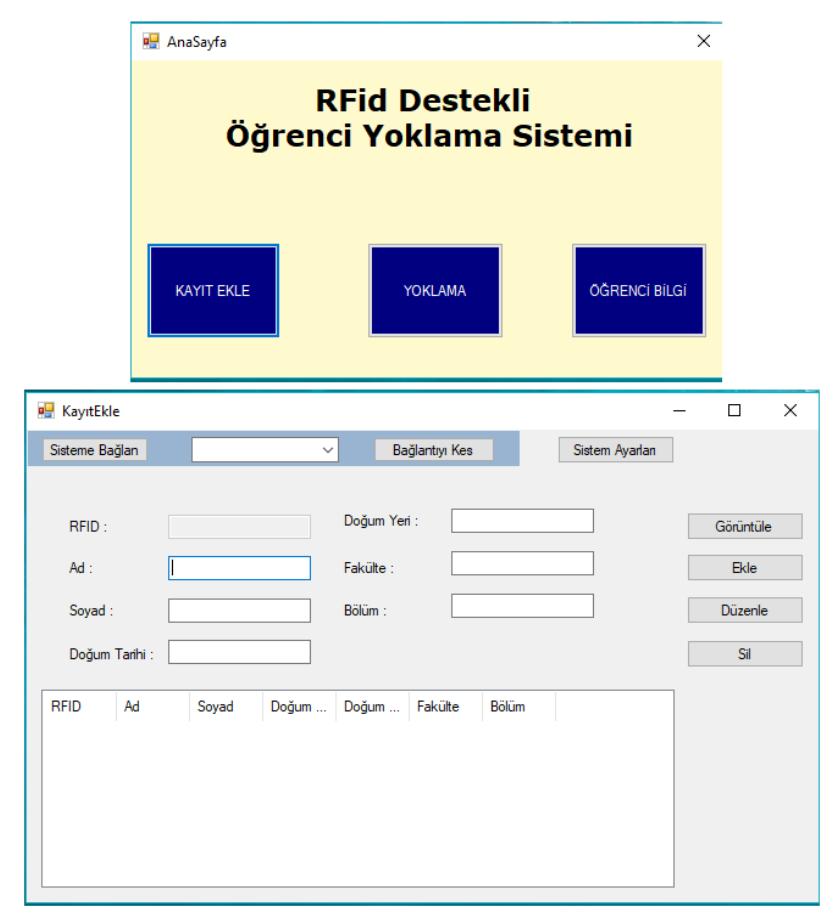

Figure 3. Student Attendance Form Screens

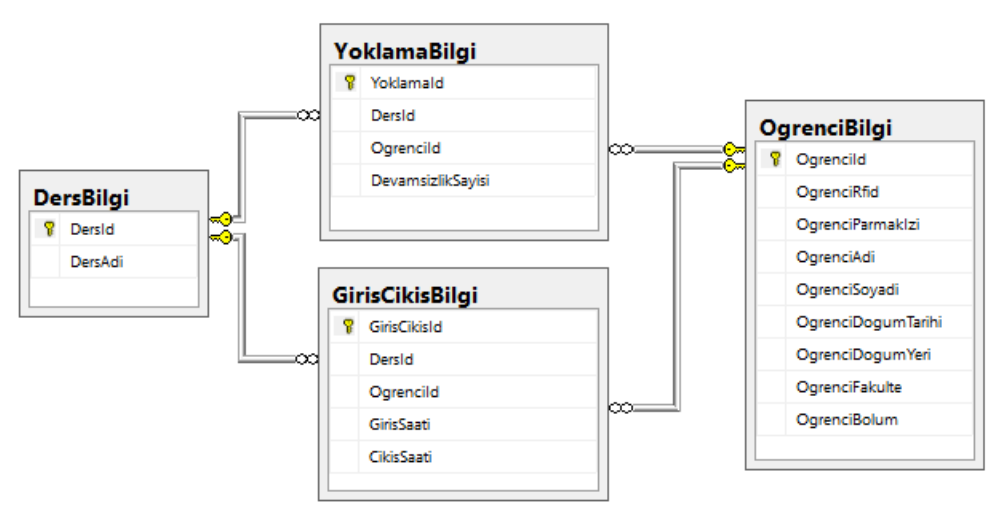

Figure 4. Student Attendance Management System Database Design

\section{Student Attendance Management System Working Structure}

After the design and coding processes, a test system was established. The connection scheme of the developed student attendance system is shown in Fig 5. In this hardware system, there are one Arduino Uno card, one RFid sensor, one fingerprint sensor and two leds (red and green). It is necessary to register the card and fingerprint information in the database before the system starts to work. Database problems that may be encountered on this way can be resolved in advance. 


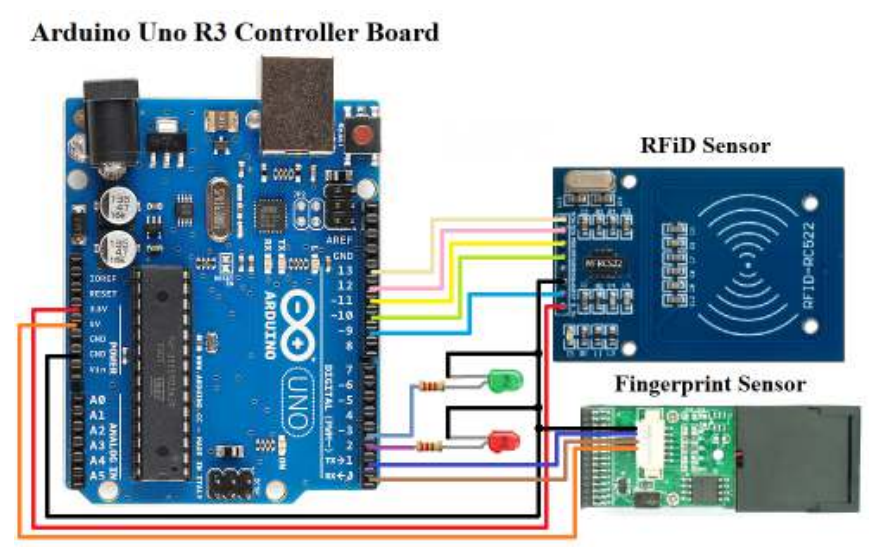

Figure 5. Connection Scheme of Student Attendance Management System.

Let us look at the student attendance system, firstly, student card with RFid tag is read and student entry is done. In this way, it is checked whether the student is at the class. Then the fingerprinting system becomes active by reading the master card at the teacher. In this case, students need to use the system again and perform attendance process over fingerprint. Red and green leds are given warning to the user depending on the database control procedures. Thanks to this designed system, the signing problems encountered during the student attendance process have been tried to be removed. Figure 6 shows the hardware connection of the student attendance system.

Figure 7 shows the flow chart of the student attendance system. As can be seen from this figure, the student card is read, and then the query of the card is done through the database. If the card information is available in the database, the fingerprint process is started. Otherwise, the related student needs to be registered in the database with the help of $\mathrm{C} \#$ form screen. After the card reading process, the fingerprint reading process is started. If the student's fingerprint data is in the fingerprint database, a signature is placed on the student's attendance list then student information registered to database. Otherwise, fingerprint record of the student must be done.

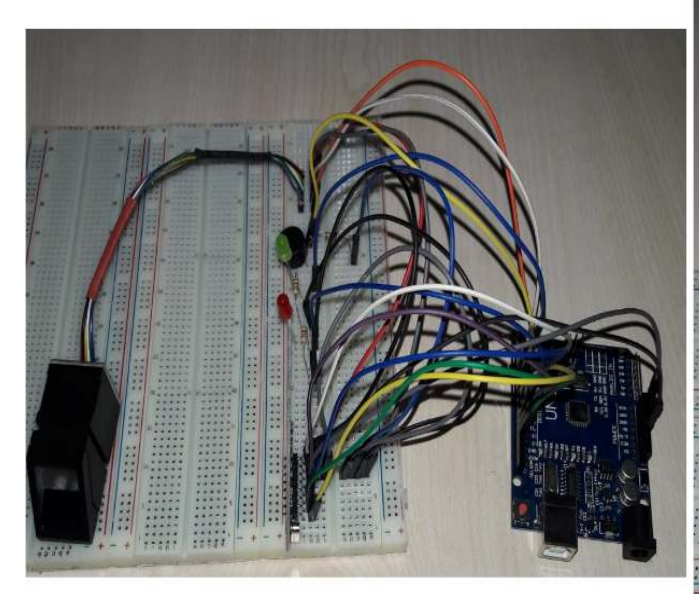

Figure 6. Hardware Connection of Student Attendance Management System

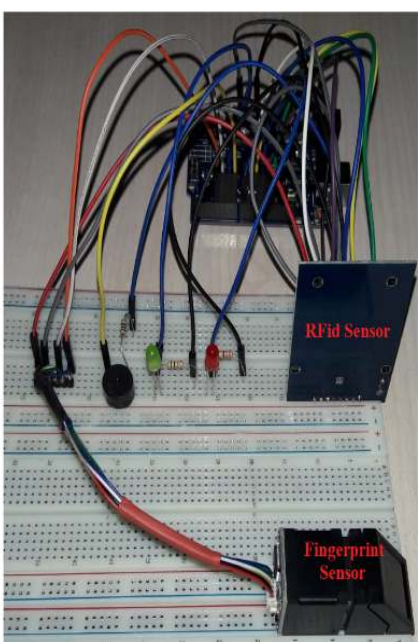




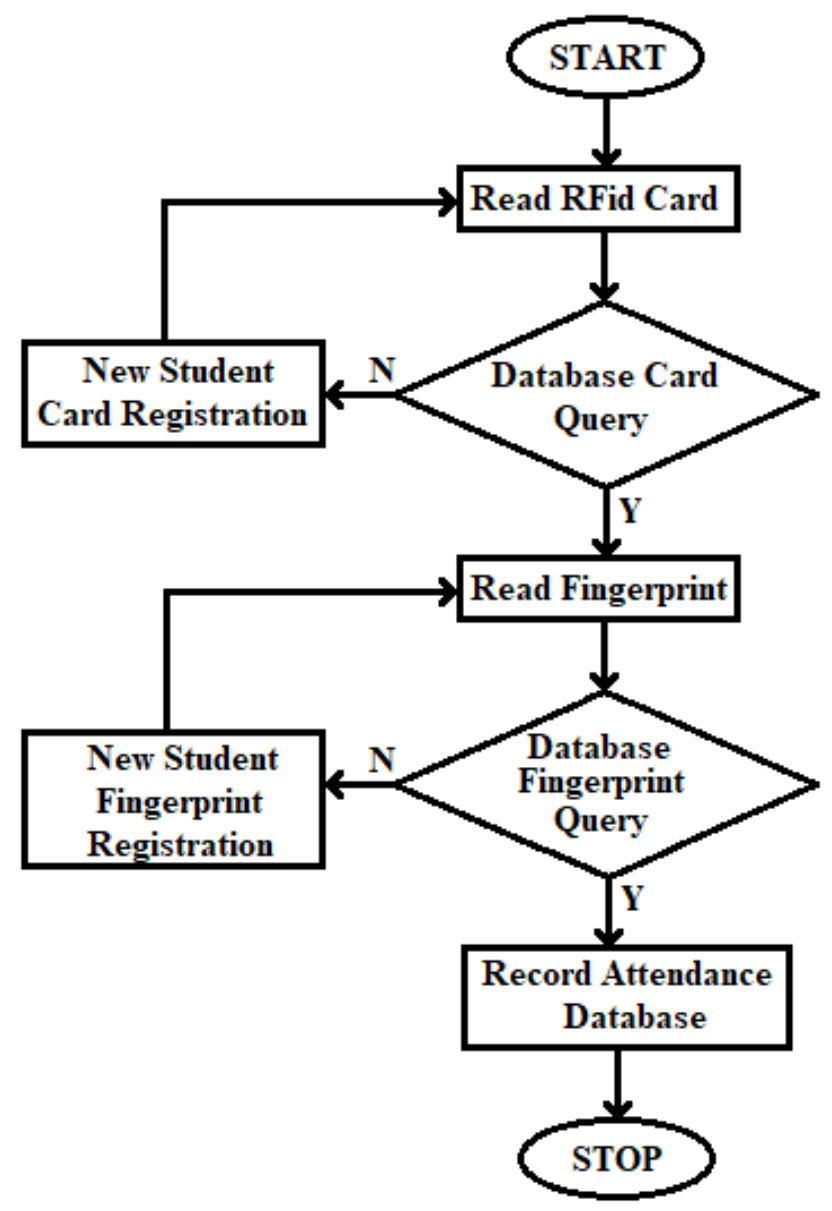

Figure 7. Flowchart of Student Attendance Management System

\section{Conclusions}

In this study, a system has been realized that is enable the students to take an attendance in the digital environment for the courses given in the schools or universities. By the student attendance management system, we have been looked for solutions to signature and card reading problems encountered during attendance procedures. The system that implemented in two stages, the student was first entered into the classroom by using the RFid card, and then the fingerprint sensor was used to perform the attendance process.

The data obtained from the sensors via the Arduino uno card is controlled by a database created in the computer environment. Three RFid cards were used in these studies and two of them were recorded in the system. A new registration process has been performed for the card that is not recorded in the tests. After the new registration, the card becomes available. The experiments with a fingerprint sensor, like the RFid card, three users were diagnosed and data was recorded for the fingerprints. In the scope of study, the student attendance management have been realized for the sample lesson and records have been saved to the database. 
In future work, the Bluetooth module will be used instead of the wired connection for transmission of data over Arduino. For database control procedures and system follow-up, mobile phones with android operating system will be used instead of computer and the output of the attendance will be sent as an e-mail.

\section{References}

[1] Öğer, C., "RFID Otomatik Tanıma Sistemleri”, http://www.otomasyondergisi.com.tr/ arsiv/yazi/rfid-otomatik-tanima-sistemleri, 2018

[2] Üstündağ, A., Tanyaş, M., "Radyo Frekanslı Tanıma (RFID) teknolojisinin tedarik zinciri üzerindeki etkileri", İTÜ Dergisi, 8(4): 83-94, 2009

[3] Sembol Barkod, “Rfid Nedir?”, http://www.sembolbarkod.net/rfid-nedir/, 2018

[4] Wikipedia, "Fingerprint", https://en.wikipedia.org/wiki/Fingerprint, 2018

[5] Özkaya, N., Sağıroğlu, Ş., "Otomatik Parmakizi Tanıma Sistemlerinde Kullanılan Önişlemler için Yeni Yaklaşımlar", Gazi Üniv. Müh. Mim. Fak. Der., vol 21(1): 11-19, 2006

[6] Pala, Z., "RFID Teknolojisi ile e-Yoklama Uygulaması", II. Uluslararası Bilgisayar ve Öğretim Teknolojileri Sempozyumu, 16-18 Nisan 2008, İzmir, Türkiye

[7] Deniz, Ö., Ceylan, O., Ulusoy, A., "RFID Kart Sistemi İle Personel Odası, Sınıf ve Laboratuvar Giriş Kontrolü", Mehmet Akif Ersoy Üniversitesi Fen Bilimleri Enstitüsü Dergisi Özel Sayı, vol. 1, pp. 134-139, 2017

[8] Baykara, M., Gürtürk, U., Karakaya, E., "NFC based smart mobile attendance system", 2017 International Conference on Computer Science and Engineering (UBMK'2017), 5-8 Oct. 2017, Antalya, Turkey

[9] Mutha, V.R., Kumar, N., Pareek, P., "Real Time Standalone Data Acquisition System for Environmental Data", 1st IEEE International Conference on Power Electronics. Intelligent Control and Energy Systems (ICPEICES-2016), 04 - 06 Jul 2016, Delhi, India

[10] Nedelkovski, D., "How RFID Works and How To Make an Arduino based RFID Door Lock", https://howtomechatronics.com/tutorials/arduino/rfid-works-make-arduino-basedrfid-door-lock/, 2018

[11] Gül, S., “Arduino İle Parmak İzi Okuyucu Sensör Kullanımı”, https://www. robimek.com/arduino-ile-parmak-izi-okuyucu-sensor-kullanimi/, 2018 